\title{
A CULTURA NO ESPAÇO VIRTUAL: NOVAS APRENDIZAGENS PARA O PROFESSOR DE ARTE
}

\author{
Maria Cristina da Rosa
}

RESUMO: Este artigo tem como objetivo propor uma reflexão acerca das transformações ocorridas na cultura a partir do ambiente virtual. Este movimento cultural exige do professor novas aprendizagens que possibilitem a utilização destes mecanismos na sua atividade pedagógica. Considera-se 0 ambiente virtual uma ferramenta para ampliar o acesso do professor de arte à informação e também como apoio para a formação continuada. Destacam-se, desta forma, as transformações ocorridas na cultura de aprendizagem convencional para as novas estratégias criadas a partir das necessidades de aprendizagem do aluno virtual, especialmente o professor em formação.

\section{As mutações do conceito de cultura:}

Cabe refletir inicialmente acerca das transformações ocorridas no conceito de cultura para que atenda à diversidade de modalidades da ação humana na atualidade, e dentro deste contexto, o estímulo para que sejam construídos mecanismos de revigoramento à medida que acontecem as mudanças na sociedade com homens e mulheres. Assim, cultura virtual vai se caracterizar pelos novos hábitos que se constituem quando os indivíduos se relacionam com os instrumentos tecnológicos das chamadas mídias. PELLANDA e PELLANDA (2000) chamam o espaço virtual de espaço cibernético, identificando- 
o como espaço de convivência da humanidade hoje. Um espaço que toma vulto na vida das pessoas e que por isso já tem importância, não só do ponto de vista cultural, social, como também econômico.

Osautoresconsideram tambémquea ampliação da inter-relação dos indivíduos com o espaço virtual vão tomar proporções maiores quanto mais se ampliar na sociedade o uso do espaço cibernético, produzindo assim transformações no campo do Trabalho ${ }^{14}$, da Educação, da Estética, da Arte e também da Política.

Ressalta-se que o espaço virtual é muito pouco utilizado se comparado a outras mídias mais populares como a televisão, por exemplo. No entanto, há que se considerar que é só uma questão de tempo até que outras parcelas da população tenham acesso à tecnologia, ainda que, como enfatiza FREITAG (2000), 2/3 da população mundial estará alijada do acesso tecnológico e, por consequiência, de muitas oportunidades do mercado de trabalho.

BENTES (1997) apresenta uma versão do impacto da mídia na cultura, quando cita as guerrilhas eletrônicas que se estabeleceram no contexto da América Latina na Guerrilha Zapatista, onde o movimento utilizava a Internet como fonte de divulgação e acesso às informações. Assim, todo o mundo ficou sabendo da Guerrilha a partir das diversas páginas da Internet que veicularam mensagens para que as pessoas pudessem acessar de forma virtual as idéias do movimento.

(14) Sobre a relação entre Trabalho, Arte e Educação ver: NUNES, 2004. 
Outro caso de acesso à informação ressaltado pelo autor é o caso da entrevista de Marcinho VP, traficante do Morro Santa Marta, no Rio de Janeiro, ao afirmar ser desnecessária a ida à universidade porque no Morro todos tinham acesso à informação, através do contato com a TV a cabo.

Nas relações complexas que se estabelecem entre cultura, capitalismo, pós-modernismo e exclusão social, globalização e transnacionalismo, é que transita a cultura virtual, porque é no espaço da virtualidade, que tais temas interagem de forma dialética. Não é possível negar o espaço virtual, porque ele possibilita vários acessos, como o caso dos Zapatistas; por outro lado, não é possível "fetichisar" o espaço virtual como se ele fosse apenas inclusivo, apenas democrático. Por conter esta diversidade de possibilidades, é que se caracteriza como um espaço dialético, pela condição de constituir-se enquanto síntese de contrários. Nesta reflexão, há um universo amplo de possibilidades para problematizar, presente na história viva da humanidade, aqui, especificamente, sendo tratadas a influência das novas mídias nas transformações do século XX a partir das transformações do conceito de cultura.

Com as marcas do século XX, como o tempo de tantas transformações num curto período, do modo de vida dos homens e mulheres, é que será situado o debate da cultura virtual. Em todos os aspectos da sociedade homens e mulheres, efetivamente, transformaram a natureza, transformaram a si próprios e produziram novos conhecimentos do ponto de vista científico, tecnológico, comunicacional, artístico, do modo de organização da sociedade, do trabalho, do ponto de vista político, e talvez o principal, do 
ponto de vista cultural.

Muitos debates no século XX apontaram para a discussão dos princípios capitalistas ${ }^{15}$, em especial o surgimento de movimentos revolucionários socialistas que colocaram em cheque os seus pressupostos. Algumas dessas revoluções socialistas persistem no cenário mundial até os dias de hoje $\mathrm{e}^{16}$, e também são incessantemente questionadas. As duas grandes Guerras Mundiais, a queda da Bolsa de Valores em 1929, a Guerra Fria, a queda do muro de Berlim, a Guerra do Golfo Pérsico, a grande Revolução Européia de 1989, também são espaços de rediscussão da nova ordem econômica, social e política. Mais próximo dos dias atuais tem-se os confrontos entre os Estados Unidos e o Iraque.

No campo específico da arte, cada movimento artístico formador das vanguardas modernistas da primeira metade do século $X X$ reconsiderou novas utopias e buscou definir em seus diversos manifestos a sobrevivência do homem neste espaço de profundas conturbações. O Futurismo propiciou e reflexão acerca da velocidade da sociedade da máquina, o Dadaísmo apostou no rompimento das tradições, bem como o Expressionismo, com a necessidade de derramar toda a dor perante as incertezas da vida humana, do ser moderno. Cada momento desses buscou seu olhar específico sobre um grande cenário de transformações que se constituiu na sociedade de forma tão rápida, se comparado aos séculos anteriores à era moderna. Assim, esses movimentos reuniram características de muitos conflitos e nenhuma linearidade.

(15) HOBSBAWM, 1994.

(16) Como o caso de Cuba, que mesmo com algumas ressalvas avançou nos aspectos de saúde e educação. 
Picasso apresenta seu ponto de vista em relação à guerra, uma busca por definições sociais. Seu desconforto com a dizimação da população da cidade espanhola de Guernica fez com que o artista se manifestasse em sua linguagem a arte, através da apresentação do quadro intitulado "Guernica". As dores da perda humana e da dignidade social estão presentes na vida de Picasso e são traduzidas nesse quadro. Logo, a arte não se manteve neutra, foi um espaço de reflexão social, mudando a vida das pessoas e do contexto das cidades.

No processo de grandes transformações que se engendrou na metade do século $X X$, o cenário se agravou pela carnificina da Segunda Guerra Mundial. Ainda no pós-guerra, o eixo das artes plásticas saiu da cidade de Paris, que deixou de ser a capital das artes na Europa, e mudouse para Nova lorque, que passou a acolher as artes plásticas no contexto do Expressionismo Abstrato.

No movimento das transformações da sociedade e dentro dela, nas leituras da arte institucionalizada, destaca-se a do papel da idéia como principal objeto de produção artística. A arte assume novas características que vão ao encontro das fragmentações sociais. $\mathrm{Na}$ arte, a interface das linguagens, o fim das fronteiras de estilo, a diversidade de material, propostas abertas de construção e leitura da obra de arte vão caracterizar o Pós-modernismo.

Neste final de século que, já um pouco mais pacificamente, é possivel rotular de pósmoderno, tanto a tradicional concepção antropológica de cultura quanto categorias mais recentes (...) não mais dão conta, sozinhas, da 
complexidade e da diversidade da dinâmica cultural (COELHO, 2004, p.127).

$\mathrm{Na}$ arte, institucionalizada estão refletidas as características da sociedade ocidental, bem como as problemáticas do indivíduo, do multiculturalismo, da crítica ao consumismo, das idéias neo-expressionistas que ressurgem na pintura, que dão a tônica de um grande caldeirão cultural onde tudo é permitido.

A complexidade da dinâmica cultural se multiplica paralelamente a um sentimento de negação, em alguns setores, da construção de análises sobre os processos de mudanças culturais dentro da arte, como a percepção do fenômeno pós-moderno numa perspectiva ufanista, na medida em que este é visto como o redentor da arte e da sociedade porque abre os caminhos para uma ampla expressão artística e de movimento do ser humano.

Em outros contextos sociais, fora do eixo dominante, as experiências estéticas não institucionalizadas acontecem ao mesmo tempo em que as experiências da arte institucionalizada, porém, em outro cenário, com leituras diferenciadas da realidade. 0 caso da América Latina e África, Ásia e União Soviética, apresentam-se não só no universo da arte, como também no da política, com abordagens diferentes do eixo dominante.

Nas reformas de Gorbachev na União Soviética, a partir de 1985, são apontados, na conjuntura social, novos olhares para a dualidade entre as potências americanas e soviéticas, pois essas reformas vão gerar um abrandamento do regime soviético. Desde o início do projeto de abertura de Gorbachev, fica marcado o fim do regime 
IANNI aponta esse cenário como síntese da necessidade de muitas reflexões teóricas:

A partir destas questões se torna possível compreenderagrande transformaçãoqueseacha em curso nesta parte da história. Aos poucos, fica evidente que terminou uma época, mas não terminaram os desafios. Ao contrário, eles se recriam com novos ingredientes. Reabremse as disputas entre nações capitalistas. A Alemanha e o Japão surpreendem e já parecem incomodar os Estados Unidos e a Europa. Os Estados Unidos dão sinal de declínio, aquém da missão civilizatória global que procuravam assumir (1999, p. 21).

Os novos desafios aos quais lanni se refere dizem respeito a uma série de aspectos que vão desde as necessidades comerciais criadas pelos países da América Latina, África, China, Oriente Médio, até questionamentos acerca da capacidade do capitalismo de estancar as desigualdades sociais da maioria da população mundial.

IANNI (1999) assinala uma reorganização da história. Apresenta a substituição da visão de sociedades nacionais pela visão de sociedades globais. Este fenômeno, mais conhecido como "globalização", muda o conceito de fronteira entre os diversos países. A formação de blocos de países, o fim das barreiras de impostos e o livre comércio são aspectos desta nova ordem global que vão influenciar o contexto cultural no que diz respeito ao modo de vida dos homens e mulheres.

O autor não considera a globalização como um fato acabado, pois, como pressuposto da 
globalização, está a necessidade de efetivarse um desenvolvimento por toda a sociedade sem excluir países deste processo. Dessa forma, observa-se que a globalização proposta nasce excludente, sendo que esse projeto de exclusão está longe de acabar.

Este é o caso da África e da América Latina. 'Globalização - o termo que define a economia dos anos 1990 - é hoje inadequado. Em verdade, as economias das nações industrializadas têm-se tornado crescentemente interligadas, por meio do comércio global e dos produtos globais. Mas a globalização deixou bastante à parte duas imensas regiões do globo, compreendendo mais de 60 países, com cerca de 20\% da população mundial e uma respeitável parcela dos seus recursos naturais: África e América Latina (...). (BELLI apud. IANNI, 1999, p.23).

No processo de globalização, as grandes potências, formadas pelos países mais ricos do mundo, Estados Unidos, Inglaterra, Alemanha, Japão, França, Itália, Canadá e mais recentemente a Rússia, promovem uma reorganização do capitalismo, a partir da necessidade de formação de blocos, superpotências, de abertura de novos mercados.

Fundamentadas na crítica ao Estado-Nação e por consequiência no Estado do Bem-Estar Social, desenvolvem um projeto com vistas à flexibilização das relações de trabalho. As relações estáveis de trabalho com vínculos de seguridade social entre trabalhadores, governo e empresas vão dar lugar a relações estabelecidas através de contratos esporádicos, por empreitadas de trabalho e vínculos temporários sem ônus trabalhistas para o empregador. Como principal argumento, as elites dominantes vão usar o fato de que a flexibilização é necessária para ampliar 
as competências dos trabalhadores, pois se não houver estabilidade, estes estarão a todo tempo buscando capacitar-se, ficando para o mercado a tarefa de escolher entre os mais capacitados.

Através dos princípios neoliberais é que as nações dominantes criam estratégias para a monopolização da economia mundial. Desse modo, vão sustentar sua política de relações trabalhistas normalmente mudando o eixo de contratação para países de terceiro mundo, onde a mão-de-obra e a matéria-prima são mais baratas e o nível de organização dos trabalhadores é menor, se comparado aos países ricos.

Do ponto de vista das questões ambientais, os países de "terceiro mundo" também são utilizados como depósito dos dejetos produzidos pelas grandes indústrias multinacionais. Percebese, também, que a fiscalização ambiental nos países pobres deixa a desejar no que se refere à proteção do ambiente.

IANNI (1999) define três formas, épocas ou ciclos de grande destaque do capitalismo, sem que necessariamente cumpram uma ordem linear entre elas; podem sobrepor-se, conviver ou mesclar-se. Inicialmente este processo de modernização se constitui de forma a opor-se ao modelo agrário, dando ares de modernidade às relações entre capital e trabalho, constituindose como um campo fértil para a revolução burguesa.

Num segundo momento, o capitalismo busca aumentar suas fronteiras, conquistar novos mercados e aprimorar as relações comerciais internacionais. Amplia seus espaços de produção além-mar, estabelece formas de obtenção de matéria-prima mais abundante e com custos 
mais baixos. Desta forma, a desenvoltura do capitalismo sobre a economia nacional estabelece como estratégia de conquista o poder sobre outras nações de menor poder no cenário global. Tal categoria é definida como imperialismo, configuração histórica dada por IANNI (1999), a partir das reflexões de Hobson, Bukharin, Rosa Luxemburgo e Lênin, onde predomina a lei do mais forte sobre o mais fraco.

Como terceiro destaque, o autor identifica o capitalismo numa escala global. Os EstadosNações declinam de parcelas de seu poder, tanto os países dominados quanto os países dominantes, em nome de organizações que detêm 0 maior poder econômico.

As empresas e os conglomerados constituemse como centros de decisão, ampliando seus poderes à proporção que se alastram por vários países perdendo um vínculo único, com um determinado país. Adquirem a formatação da necessidade econômica, adaptando-se aos modos de vida de cada país, onde a necessidade exige que se instalem e se incorporem ao mercado nacional ou regional. Constituem-se, desta forma, poderes dentro de uma sociedade global.

ParaIANNI, “Umasociedadeglobalnosentido de que compreende relações, processos e estruturas sociais, econômicas, políticas e culturais, ainda que operando de modo desigual e contraditório" (1999, p. 39). O último aspecto levantado pelo autor interessa particularmente a este artigo, pois é nesse contexto que estão estabelecidas as necessidades de novas aprendizagens culturais, a partir da chamada sociedade global que vem, ao longo do tempo, produzindo modos de vida entre as pessoas, ampliando as redes de acesso a determinadas informações, onde os indivíduos 
estão conectados mundialmente através da Internet. Esse ambiente, aliado ao conceito de desterritorialização, produzem uma nova ordem cultural de relação entre os indivíduos. Como identifica IANNI: "Há situações e momentos nos quais as determinações econômicas adquirem preeminências, tornam-se particularmente visíveis, decisivas. Mas sempre levam consigo implicações sociais, políticas e culturais" (1999, p. 39).

\section{Mudança cultural: fenômenos desterritorializados}

ORTIZ (1998) aponta uma questão central que é a reflexão acerca da realidade mundial na perspectiva da cultura dissociada de um determinismo econômico. Como tratar então a complexidade da cultura neste contexto mais amplo das diversas identidades culturais? Existe a possibilidade de uma cultura mundial? Como é possível constituir um sentimento de pertença a uma sociedade mundial? $E$ as questões de identidade, como se estabelecem neste contexto?

Dentro do atual pensamento antropológico, o aspecto de singularidade se mantém. Para ORTIZ,

Cada 'povo' é uma entidade, um 'mundo' diverso dos outros. Decifradores de uma linguagem oculta, os antropólogos se vêem como estudiosos das diferenças. A categoria cultura lhes permite dar conta desta pluralidade dos modos de vida e do pensamento (1998, p. 21).

O autor identifica a resistência entre os antropólogos à compreensão de uma idéia de mundialização da cultura, que para ORTIZ (1998) diz respeito a um conjunto de manifestações 
que se estabelecem no modo de vida de grupos sociais, vistos até hoje sob uma ótica singular.

Assim, é de suma importância tentar perceber como se constitui a reflexão posta por ORTIZ (1998) na perspectiva da mundialização da cultura, onde o autor identifica que o termo globalização, para dar conta desse cenário de transformações culturais, é restritivo, na medida em que está impregnado, neste conceito, a supremacia das questões econômicas. Sem desconsiderar a importância das análises econômicas, deseja ampliá-las a partir do conceito de mundialização da cultura.

Para demarcar o campo da cultura e não tornála uma conseqüência das questões econômicas, o autor aborda a perspectiva das origens do capitalismo no século XV, não havendo, a partir destas origens, uma determinação cultural possível de influenciar o século XVIII ou, da mesma forma, as origens modernas no século XX. Ressalta que cada período foi caracterizado por uma diversidade de mudanças culturais, do ponto de vista do indivíduo, das relações culturais, da organização da cidade. Situações que se modificaram completamente, no sentido de transformar-se em outra coisa, enquanto as relações econômicas, do ponto de vista do capitalismo, modificaram-se, porém nunca deixaram de ser capitalismo. Assim, o autor aponta a inexistência de um determinismo econômico sobre a cultura.

Isto significa que a história cultural das sociedades capitalistas não se confunde com as estruturas permanentes do capitalismo. 0 século XIX conhece expressões diferenciadas

(17) Grifo do autor. 
de seu início, com o nascimento da sociedade industrial, e no seu final, com a emergência da modernidade urbana e o take off ${ }^{17}$ da Segunda Revolução Industrial. E se hoje o tema da pós-modernidade se impõe é porque no âmago deste mundo que descrevemos como sendo capitalista surgem outras configurações irredutíveis ao processo econômico (ORTIZ, 1998, p. 24).

Nesta perspectiva, a mundialização da cultura mantém a existência da diversidade, a possibilidade de coexistência de várias manifestações culturais, mesmo que isso aconteça com situações de conflito. No entanto, não desconsidera que existam aspectos da cultura que são, na atualidade, por força da Rede Mundial de Computadores - WEB, disseminados de forma mais rápida.

Desconsiderar o acesso à rede mundial de informação como espaço de construção da cultura nos dias atuais é praticar um reducionismo na compreensão de um novo modo de produzir cultura ou, melhor dizendo, um espaço de troca de cultura. Mesmo que milhões de pessoas não tenham acesso algum a este meio, e que outras tantas nunca cheguem a tê-lo, as que tiverem acesso modificarão seus modos de relacionar-se com a informação, e esse fator torna importante estudar como se dão as relações culturais do ponto de vista de uma interação mediada pela tecnologia.

Para RIBEIRO (2000), é de fundamental importância perceber como o espaço virtual modifica as relações culturais entre os indivíduos. $\mathrm{O}$ autor analisa as transformações que o espaço virtual produz sobre as relações subjetivas, as necessidades sociais, econômicas, institucionais, 
ideológicas, individuais e coletivas.

Assim, o autor diferencia os termos globalização e transnacionalismo. Para ele, o primeiro identifica as questões ligadas à economia e o segundo identifica as questões ligadas à cultura. Pode-se fazer uma correlação entre o conceito de transnacionalismo utilizado por RIBEIRO (2000) e o conceito de mundialização da cultura empregado por ORTIZ (1998), posto que ambos diferenciam os aspectos mais usuais para falar das questões econômicas, relativamente separados dos aspectos do âmbito da cultura, delimitando dois termos para isso. Ambos partem de um conceito de globalização. Para os aspectos subjetivos e culturais, Ribeiro utiliza transnacionalismo e Ortiz mundialização.

RIBEIRO manifesta-se em relação às articulações entre transnacionalismo e a Internet, observando que:

De fato, o transnacionalismo tipicamente manifesta-se através de uma articulação diferente do espaço real e da criação de um novo domínio de contestação política e ambiência cultural que não são equivalentes ao espaço que normalmente experimentamos: assim os chamados ciberespaço e cibercultura. Esta é a razão por que a base tecnosimbólica para a emergência do que chamo de comunidade transnacional imaginada-virtual é a rede global de computadores, a Internet (...) (2000, p. 468).

Quando da criação da rede global de computadores, a Internet foi pensada inicialmente do ponto de vista da estratégia militar, como alternativa comunicacional mais rápida para ampliar as redes de informação do exército americano. Neste contexto, a 
abertura da rede para outros fins, científicos, acadêmicos ou mesmo de lazer, não se constitui um campo aberto onde não existem oprimidos ou opressores.

Do ponto de vista do acesso à rede percebese que existe uma concentração entre os estadunidenses no acesso aos computadores e que na América Latina e África este uso é infinitamente menor. Observa-se que na condição de acesso reduzido há dificuldade de buscar um equilíbrio no que diz respeito aos temas veiculados do ponto de vista da identidade cultural. De um lado, há uma diversidade de aspectos informacionais, e de outro, a ineficácia de políticas de alteridade cultural, onde todos permanecem com o direito de apresentar seus aspectos culturais e simbólicos, discutindo-os a partir da diferença de cada grupo social.

SILVA (1999) ressalta que as relações de poder são estabelecidas no momento em que os indivíduos dão significação aos aspectos sociais. Os diferentes grupos se relacionam a partir daquilo que é significativo dentro do seu meio. Por força dos contatos estabelecidos entre os grupos manifesta-se a diferença. Assim, o grupo que domina pela coerção ou pela aceitação do outro grupo, tenta impingir seu contexto para outros grupos sociais. Como exemplo desta prática, na realidade ocidentalizada, pode-se apresentar a mudança de hábitos, não só de comportamento, mas alimentares, de modos de vestir diferenciados, a partir da entrada da mídia no Brasil, no que diz respeito aos modos de viver da juventude americana.

Estabelecer uma identidade entre grupos diferenciados é conquistar no diferente o desejo de abrir mão do seu significante cultural, 
partilhando da representação do outro através da eliminação do contraste.

A identidade tal como a cultura, tampouco é produto final, acabado, uma coisa. Ela é objeto de uma incessante construção. Os resultados dessa construção, tal como as práticas de significação a que está vinculada, são sempre incertos, indeterminados, imprevisíveis. Como diz Stuard Hall (1994, p.222), deve-se pensar na identidade como uma 'produção, que não está nunca completa, que está sempre em processo, e é sempre constituída no interior, e não fora da representação (SILVA, 1999).

Percebe-se, então, que outras significações vão fazer parte do universo das relações de troca que acontecem no âmbito da Internet. Essas trocas são articuladas por uma nova postura diante da tecnologia, novos hábitos que se constituem, ou seja, uma outra forma de relacionar-se.

Nas considerações da cultura virtual identificase que as possibilidades de participação são talvez os maiores valores do mundo virtual, ainda que também possam produzir um confinamento do indivíduo, ou seja, das possibilidades de atuar democraticamente dentro na Internet. A esse respeito, FISHKIN (2002) aponta que existem várias possibilidades de participação no contexto da Rede Internacional de Computadores - WEB, desde espaços virtuais que consultam sob diversos aspectos da vida cotidiana, até processos de eleição que proporcionam mudanças na sociedade. Ressalta, no entanto, que mesmo que as pessoas tenham possibilidade de utilizar os mecanismos de participação, esta participação é perpassada pelos aspectos econômicos e sociais, daqueles que têm acesso à Internet. Os "votos", ou seja, a participação pela Internet, fica à mercê da organização do processo, podendo ser 
ou não manipulada pelos organizadores.

As formas de participação popular na mídia são algo há muito tempo utilizado pelas rádios, por exemplo, para atingir principalmente as classes populares, pois alguns programas têm sua seleção produzida com a participação dessas pessoas no cotidiano das rádios. Alguns programas utilizam os cardápios musicais como atrativos para obter a atenção das pessoas que ligam para solicitar uma determinada música e outras que as oferecem para outras pessoas de seu círculo de relações. "Diferentes meios exigem dos indivíduos que utilizem diferentes habilidades, faculdades e recursos a fim de codificar e decodificar mensagens no referido meio" (THOMPSON, 1995, p. 223).

É importante salientar que os "gostos" a partir das músicas que são solicitadas às rádios são estimulados pelas canções que ficam mais expostas na mídia, seja pelos próprios programas, ou ainda, pela própria televisão nas trilhas de novela. Mas o que é necessário destacar é que esse mecanismo de participação vai estenderse na atualidade de forma muito mais ampla do que as experiências de rádio, porque amplia demasiadamente a participação, pelo telefone e também pela Internet. Surge aí outra experiência cultural, na medida em que as pessoas não ficam mais passivamente assistindo à programação. A todo o momento é solicitada uma opinião para identificar a expectativa do público e mantê-lo fidelizado à programação.

Pode-se dizer, então, que a participação virtual na utilização do telefone, quando se fala com um Centro de Atendimento ou a participação na Internet, modificam as relações culturais. Esta perspectiva produz uma mudança no corpo 
que se comportava de forma mais acomodada no sofá da sala. A própria saída para o telefone ou a Internet, quando a programação solicita, faz com que os telespectadores se movimentem corporalmente para participar.

De tal modo, as novas tecnologias da comunicação permitem colocar diferentes parceiros de interlocução em contato, através de ações recíprocas e vínculos virtuais variados, criando um potencial de interação inédito, se comparado com os veículos de comunicação tradicionais (MAIA, 2002, p. 46).

Nas perspectivas do conceito de cultura apontado por LARAIA (1986), a própria condição dos internautas faz com que, a partir das condições de comunicação existentes entre eles, construam-se novas formas de comunicação entre o grupo. Nesse cenário a rapidez de possibilidades de troca também mudará a forma de se relacionar com o conhecimento.

Neste momento de intensas mudanças culturais influenciadas pela linguagem e modos de aprendizagem da Internet, surgem novos elementos de interação na cultura simbólica que farão parte do cotidiano das pessoas.

Ainda Lévi (1993) indica que qualquer reflexão sobre o futuro da cultura contemporânea não pode ignorar a enorme incidência de meios eletrônicos e da informática. No que se refere às novas tecnologias de comunicação com suporte informático, o autor acredita que o hipertexto representa um dos futuros da escrita e da leitura, pois o hipertexto ou a multimídia interativa adequam-se particularmente aos usos educativos (PORTELLA, 2002, p. 128).

Considera-se que quando maior for a 
capacidade de interatividade entre os envolvidos no processo de utilização da Internet e as possibilidades de ferramentas multimídia, maior será a mudança cultural, pois estes elementos de interatividade vão modificar o universo simbólico, no sentido de estruturar a reflexão dos alunos numa perspectiva espacial diferenciada.

\section{Novas aprendizagens na ação pedagógica do professor:}

Na proposição de programas de aprendizagem para o professor, assim como nos demais processos de $\mathrm{EaD}$ o processo é centrado no aluno, em suas necessidades, porém o professor é o responsável em propor as situações de aprendizagem. Cabe ressaltar que a educação à distância possibilita que o aluno, por meio de suas escolhas ao longo do processo constitua modos de aprender cada vez mais autônomos, o que não quer dizer abandonados. O aluno tratado neste artigo é o professor que, como modo de construir sua formação continuada, opta pela educação à distância. Este modelo que não substitui as aprendizagens presenciais, pode ser uma ferramenta de ampliação e familiarização do professor em processo de estudo, com os meios tecnológicos de aprendizagem.

Alguns elementos podem facilitar a aprendizagem do professor nos processos de EaD, entre eles pode-se destacar o acesso adequado à tecnologia, uma comunicação de qualidade entre o grupo, monitores, tutor. Outro aspecto diz respeito ao acesso a materiais impressos, vídeos e instrumentos de troca à distância como chats e fóruns. Por outro lado, é necessário que este professor-aprendiz seja comprometido com as atividades propostas nos ambientes virtuais, seja reflexivo, flexível e sensível às mudanças 
sociais já abordadas nos tópicos iniciais deste texto.

Outras características que o sistema de EaD deve possibilitar ao professor- aprendiz é possibilitar uma engenharia pedagógica colaborativa, interativa com conteúdo relevante. Nos aspectos de conteúdos apresentados no ambiente virtual ganha em qualidade se buscar relacionar-se com o contexto da prática pedagógica do professor aprendiz. Este fator encoraja o professor-aprendiz a trocar e exercer sua autonomia.

Uma mudança cultural também abriga uma mudança educacional, pois hoje muitas pessoas têm como única fonte de informação as tecnologias midiáticas, como a TV e o rádio de uma forma mais popular, e a Internet, nas classes média e alta ou àqueles que a ela têm acesso no trabalho ou na escola.

Considera-se importante contextualizar este apanhado teórico-prático exposto neste artigo acerca dos processos de educação de professores que atualmente buscam nos ambientes de Educação a Distância - EaD, uma nova possibilidade de ampliação do repertório pedagógico dos professores. Cabe ressaltar que este artigo se localiza no cenário de transformação cultural que o indivíduo da educação presencial passa a constituir seu processo de educação continuada nos ambientes virtuais. Parece prudente destacar que esta mudança de lócus de formação vai influir no modo de aprender, bem como, no modo de ensinar posteriormente a este processo de educação não presencial ou ainda semi-presencial.

Mesmo não sendo objetivo deste artigo 
alongar-se nas necessidades diferenciadas do estudante de $\mathrm{EaD}$, neste caso específico a educação de professores, cabe ressaltar que existe toda uma arquitetura pedagógica pensada para e com este profissional que busca a EaD como cenário de aprendizagem.

Destaca-se como último aspecto relevante deste texto, a identificação das mudanças culturais e mais especificamente a cultura virtual como resultado de aprendizagens constituídas no âmbito do contexto atual em setores da sociedade cibernética. Como se constituem os processo de aprendizagem na cultura virtual podem ser fonte de novas pesquisas nos ambientes de EaD.

\section{Referências:}

BENTES, Ivana. Globalização eletrônica e América latina. In: Signos plurais: mídia arte e cotidiano na globalização. São Paulo: Experimento,1997.1124.

COELHO, Teixeira. Dicionário crítico de política cultural. São Paulo: Iluminuras, 2004.

FISHKIN, James S. Possibilidades democráticas virtuais. In.:EISENBERG, José e CEPIK, Marco. (Org.). Internet e política: teoria e prática da democracia eletrônica. Belo Horizonte: Editora UFMG, 2002. 17-45.

FREITAG, Bárbara. Era informacional e Ciências Cognitivas. In: Anais do II Congresso Internacional de Educação do Colégio Coração de Jesus, Ética e educação, Brasil Outros 500. Fpolis: Palotti, 2000. 26-34.

HOBSBAWN, Eric. A Era dos Extremos. São Paulo: Companhia das letras, 1994.

IANNI, Octávio. A sociedade global. Rio de Janeiro: Civilização Brasileira, 1999.

LARAIA, Roque de Barros. Cultura um Conceito Antropológico. Rio de Janeiro, Jorge Zahar Ed, 
1986.

MAIA, Rousiley C.M. Redes cívicas e Internet: Do ambiente informativo denso as condições de deliberação pública. In: EISENBERG, Jose e CEPIK, Marco. (Org.). Internet e política teoria e prática de democracia eletrônica. Belo Horizonte: Editora UFMG, 2002. 46-72.

NUNES, Ana Luiza Ruschel. Trabalho, arte e educação: formação humana e prática pedagógica. Santa Maria: Editoraufsm, 2003.

ORTIZ, Renato. Mundialização da cultura. São Paulo: Editora brasiliense, 1998.

PELLANDA, Nize Maria e PELLANDA, Eduardo Campos. Ciberespaço: um hipertexto com Pierre Lévy. Porto Alegre: Artes e Ofícios, 2000.

PORTELLA, Adriana. Aprendizagem da arte e o museu virtual do projeto Portinari. In.: BARBOSA, Ana Mae. (org.). Inquietações e mudanças no ensino da arte. São Paulo: Cortez, 2002. 123138.

RIBEIRO, Gustavo Lins. Política cibercultural: ativismo político a distância na comunidade transnacional imaginada-virtual. In.: ALVARES, Sonia. (et. Alli.). Cultura e política nos movimentos sociais latino-americanos. Belo Horizonte: Editora da UFMG, 2000. 465-502.

THOMPSON, John B. Ideologia e cultura moderna: teoria social crítica na era dos meios de comunicação de massa. Petrópolis, RJ: Vozes, 1995.

TOMAZ, Tadeu da Silva. O currículo como fetiche: a poética e a política do texto curricular. Belo Horizonte: Autêntica, 1999. 